\title{
Motivasi berolahraga atlet atletik dan tinju
}

\author{
Jusuf Blegur $^{1 *}$, Ramona Mathias Mae ${ }^{1}$ \\ ${ }^{1}$ Fakultas Keguruan dan Ilmu Pendidikan, Universitas Kristen Artha Wacana. \\ Jalan Adisucipto, 147, Oesapa, Kupang, Indonesia \\ * Corresponding Author. Email: jusufblegur@ukaw.ac.id \\ Received: 8 October 2017; Revised: 3 July 2018; Accepted: 10 July 2018
}

\begin{abstract}
Abstrak
Tujuan penelitian ini adalah untuk melakukan uji perbandingan motivasi berolahraga antara atlet atletik dan atlet tinju di Pusat Pendidikan dan Latihan Pelajar Provinsi Nusa Tengara Timur dengan melibatkan 26 orang sampel (13 atlet atletik dan 13 atlet tinju). Penelitian ini menggunakan pendekatan kuantitatif dengan desain komparatif. Data penelitian dikumpulkan menggunakan The Sport Motivational Scale (SMS) yang dikembangkan oleh Luc G. Pelletier, Michelle Fortier, Robert J. Vallerand, Nathalle M. Briere, Kim M. Tuson, dan Marc R. Blais pada tahun 1995. Hasil penelitian menunjukkan bahwa motivasi berolahraga atlet atletik dan tinju tergolong baik, masing-masing $69.2 \%$ dan $92.3 \%$. Nilai rata-rata atlet tinju lebih tinggi daripada atlet atletik, namun nilai standar deviasi atlet atletik lebih tinggi daripada atlet tinju. Secara umum, tidak ada perbedaan yang signifikan antara ratarata variabel motivasi berolahraga atlet atletik dan atlet tinju $(0.703>0.05)$. Akan tetapi, pada sub variabel motivasi intrinsik-to experience stimulation, terdapat perbedaan yang signifikan $(0.004<0.05)$ dari kedua kelompok sampel penelitian.
\end{abstract}

Kata kunci: motivasi, olahraga, atlet, atletik, tinju.

\section{Sport motivation of athletic and boxing athleetes}

\begin{abstract}
The objective of this research is to do a comparison test between athletic and boxing athletes' sport motivation in Student Education and Training Center, East Nusa Tenggara by involving 26 athletes as the sample (13 athletic athletes and 13 boxing athletes).This research used quantitative approach with comparative design. Data was collected using The Sport Motivation Scale (SMS) created by Luc G. Pelletier, Michelle Fortier, Robert J. Vallerand, Nathalle M. Brierre, Kim M. Tuson, and Marc R. Blas in 1995. The result indicates that the level of athletic and boxing athlete's' sport motivation was good, respectively $69.2 \%$ and $92.3 \%$. The average value of the boxing athletes is higher than the athletic athletes while the standard deviation value of the athletic athletes is higher than the boxing athletes. Generally, there is no significant difference between sport motivation toward the two sample groups $(0.703>0.05)$. However, there is a significant difference $(0.004<0.05)$ in sub-variables of intrinsic motivation to experience stimulation from both research sample groups.
\end{abstract}

Keywords: motivation, sport, athletes, athletic, boxing.

How to Cite: Blegur, J., \& Mae, R. (2018). Motivasi berolahraga atlet atletik dan tinju. Jurnal Keolahragaan, 6(1), 29-37. doi:http://dx.doi.org/10.21831/jk.v6i1.16150

http://dx.doi.org/10.21831/jk.v6i1.16150

\section{PENDAHULUAN}

Setiap atlet yang terlibat dalam kegiatan olahraga prestasi menginginkan prestasi itu sendiri. Prestasi merupakan impian bagi atlet ketika tampil dalam pentas olahraga, baik dalam olahraga individu maupun olahraga beregu. Prestasi ialah cerminan dari kualitas proses latihan yang telah dilewati atlet, baik itu pada aspek fisik, teknik, taktik, maupun mental. Keempat komponen latihan ini, adalah bagian penting dalam proses latihan dan saling berkaitan satu dengan lainnya. Kondisi fisik yang prima, perlu ditunjang dengan penggunaan teknik dan taktik yang memadai, serta afirmasi mental merupakan posisi 
akhir dari piramida prestasi olahraga. Selain faktor fisik dan kondisi pelatihan, Bhagirathi (2008) menegaskan bahwa keberhasilan dan kegagalan atlet tergantung pada persiapan mental dan kemampuan untuk tetap maksimal meski di bawah tekanan.

Keberhasilan maupun kegagalan atlet dalam situasi kompetitif cenderung dipengaruhi oleh motivasi dan prestasi (Davies \& Armstrong, 1989). Keberhasilan sendiri dapat diukur dengan torehan waktu atau nilai yang diukir atlet dalam kompetisi. Prestasi dapat berupa juara atau memenuhi target atau standar minimal yang telah ditetapkan oleh sebuah organisasi olahraga tertentu. Prestasi adalah hasil yang dicapai oleh individu yang telah memenuhi kaidah-kaidah pengukuran, baik secara kuantitatif maupun kualitatif. Misalkan saja, atlet atletik di nomor 1500 meter harus mencapai waktu 4.45 detik bila ingin melenggang bebas menuju kompetisi nasional (PON). Untuk upaya tersebut, formula latihan yang diberikan pelatih secara eksternal, baik itu fisik, teknik, taktik, dan mental dilumat secara proporsional guna mencapai prestasi. Atlet "digenjot" dalam proses latihan yang matang dan sustanaibel agar menampilkan performa terbaiknya. Motivasi, keseriusan, semangat, kegigihan, pantang menyerah adalah sifat dasar yang harus dimiliki atlet jika ingin berprestasi.

Sejumlah ahli psikologi olahraga sepakat bahwa dalam berkompetisi, motivasi sangat menentukan keberhasilan atlet. Motivasi adalah dasar untuk semua upaya olahraga dan prestasi. Atlet berkeinginan dan bertekad untuk meningkatkan performa olahraganya, termasuk: mental, kepercayaan diri, intensitas, fokus, dan emosi (Adeyeye, Vipene, \& Asak, 2013). Motivasi berprestasi atlet bermanfaat dalam olahraga kompetitif. Ini adalah kekuatan yang bergerak dalam tugas yang menantang dan sulit untuk dicapai atlet dalam olahraga (Murtaza, Ahmad, Imran, Ahmad, \& Singh, 2013).

Obsesi prestasi selalu mendorong atlet melakukan usaha aktif guna menaklukkan tantangan-tantangan yang dijumpainya dalam latihan maupun berkompetisi, misalnya kecemasan, stres, depresi, dan traumatis. Selain itu, tugastugas yang menantang disukainya, melaksanakan dengan penuh tanggung jawab, dan terbuka terhadap segala umpan balik guna perbaikan prestasi yang telah ada. Saat mempopulerkan kegiatan olahraga dan mempromosikan partisipasi individu, motivasi merupakan fenomena penting (Kaya, Kabakci, \& Dogan, 2015), motivasi adalah alasan dari tindakan individu untuk berpartisipasi. Ini merupakan faktor pendorong suatu organisme untuk bertindak. Artinya, motivasi sebagai faktor memobilisasi manusia.

Menurut Plotnik, motivasi mencakup faktor psikologis dan fisik yang menyebabkan individu untuk bertindak dengan cara tertentu pada waktu tertentu (Kaya, Kabakci, \& Dogan, 2015). Selanjutnya, Hagger dan Chatzisarantis mengatakan motivasi mendasari perilaku terarah dan terbukti berguna dalam perubahan pemahaman perilaku dan pengaturan aktivitas fisik (Gillison, Osborn, Standage, \& Skevington, 2009). Motivasi merupakan dasar untuk semua usaha olahraga dan prestasi (Adeyeye, Vipene, \& Asak, 2013), sebagai salah satu faktor penting dan efektif untuk performa tim dan perbaikan performa olahraga (Nezhad \& Sani, 2014).

Keterlibatan individu dalam suatu aktivitas olahraga tertentu dimotoris oleh sebuah dorongan, baik yang datang dari dalam diri sendiri maupun dari luar diri. Individu dapat saja mengikuti karena memiliki kesenangan, kegembiraan, atau bahkan kepuasan jika dirinya terlibat dalam aktivitas tersebut. Bahkan individu tidak dengan tekanan atau iming-iming apapun dirinya tetap saja melakukan kegiatan tersebut dalam kesehariannya dengan senang hati. Perilaku inilah yang sering dikenal dengan istilah motivasi intrinsik. Menurut Deci, motivasi intrinsik mengacu pada proses keterlibatan dalam kegiatan murni untuk kesenangan dan kepuasan yang berasal dari dalam diri sendiri (Pelletier, et. al., 1995).

Motivasi merupakan kekuatan energi internal yang menentukan semua aspek perilaku individu. Hal ini juga berpengaruh pada bagaimana individu berpikir, merasakan, dan berinteraksi dengan individu lain. Dalam olahraga sendiri, atlet membutuhkan intervensi motivasi untuk proses latihan maupun perlombaan, bahkan motivasi secara general diterima sebagai prasyarat penting untuk mengantarkan atlet untuk memenuhi potensi dan performa pada dirinya. Motivasi dan performa olahraga memainkan peran penting, sebab tingkat stres piskis kian meningkat seiring dengan meningkatkan level kompetisi (Slathia, Singh, \& Dar, 2015), keinginan untuk mencapai kesuksesan dan olahraga adalah salah satu yang jelas. Sebuah keinginan yang kuat untuk berhasil dalam olahraga dipilih atlet akan menjadi aset besar dalam menentukan seberapa keras atlet berlatih dan seberapa keras atlet mencoba dalam kompetisi. Semua partisipasi dalam olahraga melibatkan prestasi, terlepas 
dari apakah atlet menganggap kompetisi penting atau tidak (Jarvis, 2006).

Secara umum Hessian dan Richard mengatakan motivasi adalah dasar untuk sukses dalam kegiatan rekreasi dan kompetitif dan upaya setiap atlet menuju kesuksesan dan performa yang lebih baik tergantung terhadap nilai motivasinya (Nezhad \& Sani, 2012). Sedangkan Gill menyampaikan motivasi sebagai intensitas dan arah perilaku. Intensitas perilaku mengacu pada tingkat usaha yang dibutuhkan untuk menyelesaikan tugas sedangkan arah perilaku adalah cara untuk mencapai tujuan dalam situasi tertentu (Shafizadeh \& Gray, 2011). Motivasi juga sebagai penggerak atau pendorong bagi individu untuk melakukan sesuatu. Arah menunjukkan pada apakah individu mencari, mendekati, atau tertarik pada situasi tertentu (Maksum, 2011), individu yang memiliki tingkat motivasi beprestasi tinggi memiliki kecenderungan berusaha untuk sukses, bertahan dalam menghadapi kegagalan dan mengalami kebanggaan dalam prestasi (Gill dalam Rao \& Kishore, 2014). Setiap aktivitas yang dilakukan oleh individu tidak dapat dipisahkan dengan motivasi, seperti halnya dalam olahraga. Individu yang terlibat dalam proses latihan memerlukan motivasi dan motivasi sendiri memiliki arah dan tujuan yang jelas dan kuat dalam upaya pencapaiannya.

Konsep umum yang mencakup kehendak, keinginan, kebutuhan, dorongan, dan minat adalah motivasi. Menurut Plotnik, ketika individu termotivasi, dirinya biasa menunjukkan tiga karakteristik utama, misalnya: (1) Penuh dengan energi untuk melaksanakan tindakan tertentu; (2) Mengarahkan energi mereka untuk mencapai suatu tujuan tertentu; dan (3) Memiliki perasaan dengan tingkat yang berbeda mengenai pencapaian tujuan (Kaya, Kabakci, \& Dogan, 2015).

Jika individu termotivasi untuk berprestasi, maka ia akan memberikan usaha terbaiknya melalui energi-energi mencapai prestasi, hal ini dapat termanifestasi dari proses latihan sampai pada perlombaan. Energi-energi tersebut dimaksimalkan sebaik mungkin, dengan tujuan agar targetnya (prestasi) dapat tercapai. Perasaan semangat memotivasinya agar selalu mencari perubahan terhadap peningkatan performa keterampilannya. Dengan demikian, berlatih dan prestasi merupakan suatu kebutuhan. Sebagai contoh, seorang atlet atletik nomor lari selalu berlatih keras, meskipun ia disibukkan dengan aktivitas lain (belajar atau bekerja). Cara-cara ini dapat dilihat dengan porsi dan waktu latihan yang tidak pernah terganggu, meskipun berada dalam dua kegiatan yang menuntut perhatian dan konsentrasi yang sama. Atau bahkan dengan usia yang relatif "tua" dirinya tetap menunjukkan semangat berprestasi yang sama dengan atlet lain yang secara usia berada di bawahnya.

Motivasi intrinsik didefinisikan sebagai melaksanakan suatu kegiatan untuk kepuasan yang melekat dan bukan untuk beberapa konsekuensi lain yang terpisah. Ketika termotivasi secara intrinsik, seseorang bergerak dan bertindak untuk bersenang-senang atau tertantang bukan karena faktor eksternal, tekanan, atau imbalan (Ryan \& Deci, 2000). Motivasi intrinsik mengacu pada pelaksanaan suatu kegiatan untuk kesenangan dan kepuasan (Gillet, Vallerand, Amoura, \& Baldes, 2010). Namun, atlet juga mungkin memiliki banyak alasan ekstrinsik untuk berlatih kegiatan olahraga. Dalam hal ini, perilaku diatur melalui hasil yang diharapkan tidak melekat dalam kegiatan itu sendiri (yaitu imbalan atau tekanan). Selanjutnya menurut Deci dan Ryan, motivasi intrinsik mengacu pada partisipasi secara eksklusif untuk kesenangan, menyenangkan, atau kepuasan yang berasal langsung dari kegiatan itu sendiri (Teo, et.al., 2015).

Orientasi motivasi intrinsik menggambarkan seorang individu yang berpartisipasi dalam kegiatan prestasi untuk alasan internal, misalnya, untuk bersenang-senang, kesenangan, maupun penguasaan pribadi (Amorose \& Horn, 2000). Ada literatur mengesankan yang mendukung anggapan ini dan menunjukkan motivasi intrinsik yang lebih besar dalam kondisi yang mendukung perasaan otonomi, kompetensi, dan keterkaitan (O'Rourke, Smith, Smoll, \& Cumming, 2012).

Ketika atlet termotivasi secara intrinsik, mereka berpartisipasi dalam olahraga untuk kepentingan diri sendiri. Artinya motivasi untuk keterlibatan olahraga terutama berkisar pada kenikmatan yang melekat dalam melakukan aktivitas (Duda \& Treasure, 2001). Hal intrinsik dapat memotivasi individu untuk menyumbangkan ide-ide kreatif dan inovatif (Edrak, Yin-Fah, Gharleghi, \& Seng, 2013). Hal ini terjadi sebab dirinya tidak merasa di bawah tekanan, sehingga kebebasan berpikirnya mengantarkan pada konstruksi ide-ide yang cermerlang dalam sebuah komunitas olahraga.

Selian motivasi intrinsik, ada juga motivasi ekstrinsik. Deci berpandangan motivasi ekstrinsik bertalian dengan berbagai perilaku yang terlibat sebagai alat untuk mencapai tujuan dan bukan untuk kepentingannya sendiri (Pelletier, et. al., 1995). Motivasi ekstrinsik dapat didefinisikan sebagai performa dari suatu kegiatan untuk 
mencapai beberapa hasil yang terpisah (Ryan \& Deci, 2000). Orientasi motivasi ekstrinsik menggambarkan seorang individu yang berpartisipasi dalam kegiatan prestasi untuk alasan eksternal, termasuk, untuk mendapatkan persetujuan sosial, status sosial, maupun imbalan material (Amorose \& Horn, 2000).

Motivasi ekstrinsik lebih berfokus pada unsur-unsur ekstrinsik ketika individu berpartisipasi dalam kegiatan olahraga. Strategi ini kerap diimplementasikan oleh sejumlah daerah guna mendongkrak prestasi atlet dalam kompetisi olahraga, tidak terkecuali Provinsi Nusa Tenggara Timur (NTT). Baru-baru ini dalam perhelatan Pekan Olahraga Provinsi (Porprov IV) tahun 2014, pemerintah menghadiahi rumah kepada para atlet yang berprestasi. Hal ini ada baiknya dan adapula buruknya. Jika hal ini "dibudidayakan", maka ketergantungan atlet pada hal-hal ekstrinsik lambat laun dapat memangkas motivasi intrinsiknya. Terkait dengan pemberian reward pada Porprov 2014 kemarin, menurut beberapa atlet dipandang sebagai bentuk "ketidakadilan". Atlet-atlet yang mendapatkan reward tersebut tidak sebanding dengan catatan prestasi yang telah mereka raih dalam bidang olahraga. Di sisi lain, justru atlet lain yang telah menunjukkan konsistensi prestasi tidak direward sebagaimana mestinya. Kekecewaan ini pun sempat menimbulkan kecemburuan sosial diantara sesama pelatih maupun atlet dalam melakoni proses pelatihan.

Kaitannya dengan motivasi ekstrinsik, kiritik Maksum (2011) menekankan agar dalam pemberian motivasi ekstrinsik perlu diperhatikan secara proporsional agar tidak menimbulkan problematik bagi atlet. Sebab dominasi motivasi ekstrinsik dapat merusak motivasi intrinsik atlet serta komitmennya untuk berprestasi. Kritik Maksum ini pun erat kaitannya dengan fenomena pemberian bonus di Provinsi NTT. Pemberian imbalan materialistik ini sebenarnya bernilai positif maupun negatif. Atlet-atlet yang merasa bahwa ketidakadilan pemberian bonus atau imbalan ini mulai menunjukkan kekisruannya atau "pembrontakkannya" dalam kegiatan olahraga. Jika saja atlet didorong berolahraga untuk memenuhi kebutuhan-kebutuhan secara intrinsik, maka tidak akan menimbulkan masalah dalam pembinaan prestasi olahraga. Meskipun demikian, idealnya atlet yang berprestasi diberikan penghargaan di akhir performa atau prestasi dan bukan sebaliknya. Sehingga atlet tidak terobsesi oleh imbalan yang disediakan oleh organisasi olahraga tertentu.
Bentuk lainnya dari motivasi sangat mirip dengan konsep ketidakberdayaan. Artinya, individu termotivasi tidak menganggap kontinjensi antara tindakan dengan hasil dari tindakan yang dilakukannya. Pada tahapan ini, individu mengalami perasaan ketidakberdayaan serta menimnya kontrol atas perasaan tersebut. Pada saat berpartisipasi dalam suatu kegiatan, individu tidak termotivasi secara intrinsik maupun secara ekstrinsik. Ketika berada dalam keadaan seperti itu, mereka tidak lagi mengidentifikasi alasan yang baik untuk berpartisipasi dalam proses latihan. Alhasil mereka bahkan dimungkinkan membuat keputusan untuk berhenti berlatih dari kegiatan olahraganya.

Individu yang tidak termotivasi terkait dengan proses ketidakberdayaan, di mana individu menarik usaha karena persepsi ketidakmampuan dan hilangnya sebuah kontrol terhadap kegiatan tertentu (Barkoukis, Tsorbatzoudis, Grouios, \& Sideridis, 2008). Individu dengan gejala psikologis ini mengikuti latihan dengan keadaan terpaksa. Artinya baik secara intrinsik maupun ekstrinsik dirinya tidak mendapatkan faedah dalam kegiatan tersebut. Ini menyebabkan ketidakseriusan atlet untuk berlatih. Dampak lainnya yang dirasakan adalah pergolakkan perasaan sehingga menyebabkan ketidaknyamanan yang bermuara pada "pemogokkan dan pelarian".

Meskipun demikian, seorang atlet dapat meningkatkan motivasinya dalam berolahraga dengan menetapkan tujuan dan keluar dari perasaan yang terjebak. Goal setting dapat membantu atlet untuk membangkitkan gairah motivasinya dalam berolahraga. Perasaan-perasaan bersalah harus dapat dihindari untuk membangkitkan gairah dan semangat untuk mencapai tujuan yang ditetapkan. Selain itu, secara ekstrinsik intervensi pelatih dalam memberikan kepedulian terhadap performa dan prestasi atlet dapat merangsang motivasinya. Hal ini dimungkinkan, sebab menurut Whitehead (Maksum, 2011), motivasi merupakan sebuah tangga kontinum, sehingga berpotensi untuk atlet yang tidak termotivasi pun dapat mewarisi motivasi ekstrinsik dan bahkan sampai pada motivasi intrinsik.

Pada kesempatan ini, peneliti menyentil motivasi berolahraga yang dimiliki atlet atletik nomor lari dan tinju di Pusat Pendidikan dan Pelatihan Pelajar (PPLP) Provinsi NTT. Sejauh ini PPLP Provinsi NTT sendiri telah menginventarisir atlet-atlet untuk dibimbing dan diarahkan kepada olahraga prestasi. Meskipun demikian, masih ada atlet yang belum mengikuti 
program latihan secara teratur dan bahkan ada yang telah meninggalkan pusat pelatihan tanpa diinformasikan kepada pengurus maupun pelatih. Mencermati hal ini, maka peneliti ingin mengkaji dan membandingkan variabel motivasi berolahraga pada atlet atletik dan tinju di PPLP Provinsi NTT untuk melihat dominasi dan perbedaaan tingkat motivasi (intrinsic motivation, extrinsic motivation, dan amotivation) yang dimiliki atlet dalam partisipasi olahraganya.

\section{METODE}

Penelitian ini menggunakan pendekatan kuantitatif dengan desain komparatif. Sampel yang terlibat dalam penelitian ini berjumlah 26 orang, terdiri dari 10 orang laki-laki dan 13 orang perempuan $(\mathrm{M}=16.0769$ dan $\mathrm{SD}=.97665)$ yang ditetapkan menggunakan teknik total sampling. Data penelitian dikumpulkan menggunakan The Sport Motivational Scale (SMS) yang dikembangkan oleh Luc G. Pelletier, Michelle Fortier, Robert J. Vallerand, Nathalle M. Briere, Kim M. Tuson, dan Marc R. Blais pada tahun 1995.

The Sport Motivational Scale terdiri dari 28 pernyataan dengan menggunakan skala likert yang terdiri dari 7 sub variabel, yaitu: (1) Intrinsic motivation-to know (2, 4, 23, 27), (2) Intrinsic motivation-to accomplish (8, 12, 15, 20), (3) Intrinsic motivation-to experience stimulation $(1,13,18,25)$, (4) Extrinsic motivationidentified regulation (7, 11, 17, 24), (5) Extrinsic motivation-introjected regulation (nomor: 9, 14, 21, 26), (6) Extrinsic motivation-external regulation $(6,10,16,22)$, dan (7) Amotivation (3, 5, $19,28)$.

Teknik analisis data menggunakan analisis deskriptif dan t-test dengan bantuan SPSS 20.00 for windows. Jika nilai signifikansi (2-tailed) lebih besar dari 0.05, maka Ho diterima, artinya tidak terdapat perbedaan yang signifikan antara rata-rata motivasi berolahraga atlet atletik dan tinju. Sedangkan, jika nilai signifikansi (2-tailed) lebih kecil dari 0.05, maka Ha diterima, artinya terdapat perbedaan yang signifikan antara ratarata motivasi berolahraga atlet atletik dan tinju di PPLP Provinsi NTT.

\section{HASIL DAN PEMBAHASAN}

Analisis deskriptif menunjukkan bahwa motivasi berolahraga berkisar dari nilai minimum sebesar 28 (skor terendah dikali dengan jumlah item pertanyaan) dan nilai maksimum sebesar 196 (skor tertinggi dikali dengan jumlah item pertanyaan). Selanjutnya peneliti mengkategorikan rentang nilai motivasi berolahraga menjadi 7 , antara lain: (1) Sangat tidak baik dengan rentang nilai 1.00 s.d 28,00, (2) Tidak baik dengan rentang nilai 28.01 s.d 56.00, (3) Kurang baik dengan rentang nilai 56.01 s.d 84.00, (4) Netral dengan rentang nilai 84.01 s.d 112.00, (5) Cukup baik dengan rentang nilai 112.01 s.d 140.00 , (6) Baik dengan rentang nilai 140.01 s.d 168.00, dan (7) Sangat baik dengan rentang nilai 168.01 s.d 196.00.

Hasil distribusi responden variabel penelitian (motivasi berolahraga) atlet atletik di PPLP Provinsi NTT (lihat Gambar 1).

\begin{tabular}{|c|c|}
\hline \multicolumn{2}{|c|}{$\nabla$ Tinju $\quad$ Atletik } \\
\hline Sangat baik & 8 \\
\hline Baik & $\begin{array}{lll} & 9\end{array}$ \\
\hline Cukup baik & 1 \\
\hline Netral & 8 \\
\hline Kurang baik & 8 \\
\hline Tidak baik & 8 \\
\hline Sangat tidak baik & 8 \\
\hline
\end{tabular}

Gambar 1. Analisis Deskriptif Motivasi Berolahraga Kedua Kelompok Sampel

Gambar 1 menunjukkan bahwa dari 26 responden (13 atlet atletik dan 13 atlet tinju). Pada kelompok sampel atlet tinju, dari 13 orang, responden yang memiliki motivasi berolahraga cukup baik berjumlah 4 orang $(30.8 \%)$ dan responden yang memiliki motivasi berolahraga baik berjumlah 9 orang (69.2\%). Sedangkan tidak responden yang memiliki motivasi berolahraga sangat tidak baik, tidak baik, kurang baik, netral, dan sangat baik $(0 \%)$. Dengan demikian, data menjelaskan bahwa motivasi berolahraga atlet atletik di PPLP Provinsi NTT adalah baik dengan jumlah responden sebanyak 9 orang $(69,2 \%)$. Pada kelompok sampel tinju, dari 13 orang, responden yang memiliki motivasi berolahraga cukup baik berjumlah 1 orang (7.7\%) dan responden yang memiliki motivasi berolahraga baik berjumlah 12 orang (92.3\%). Sedangkan tidak responden yang memiliki motivasi berolahraga sangat tidak baik, tidak baik, kurang baik, netral, dan sangat baik (0\%). Dengan demikian, data menjelaskan bahwa motivasi berolahraga atlet tinju di PPLP Provinsi NTT adalah baik dengan jumlah responden sebanyak 12 orang $(92.3 \%)$. 


\section{Uji Independent Sampel t-test}

Uji independent sampel $t$-test adalah sebuah pengujian sampel t yang tidak berhubungan atau bebas. Pengujian ini dipergunakan untuk menguji signifikansi perbedaan dua buah mean yang berasal dari dua buah distribusi. Sampel berbeda adalah distribusi data yang berasal dari dua kelompok yang berbeda. Penelitian ini telah menguji nilai distribusi data dari kelompok atlet atletik dan atlet tinju terhadap motivasi berolahraga (lihat Tabel 1).

Tabel 1. Hasil Pengujian $t$-test pada Kedua Kelompok Sampel

\begin{tabular}{lrrrr}
\hline \multicolumn{1}{c}{ Motivasi } & & \multicolumn{2}{c}{ Kel. Sampel } & \multirow{2}{*}{ Sig. } \\
\cline { 3 - 4 } Berolahraga & & Atletik & Tinju & \\
\hline MI-to know & $\mathrm{M}$ & 24.2308 & 25.6154 & \multirow{2}{*}{.156} \\
MI-to & $\mathrm{SD}$ & 2.24179 & 2.56705 & \\
accomplish & $\mathrm{M}$ & 21.9231 & 18.1538 & \\
MI-to exp. & $\mathrm{SD}$ & 2.69139 & 7.40322 & .097 \\
stimulation & $\mathrm{M}$ & 18.0769 & 22.3077 & \\
ME-ident. & $\mathrm{SD}$ & 4.09189 & 2.39390 & .004 \\
regulation & $\mathrm{M}$ & 25.0769 & 23.9231 & \\
ME-intro. & $\mathrm{SD}$ & 1.44115 & 3.42689 & .274 \\
regulation & $\mathrm{M}$ & 24.5385 & 23.4615 & \\
ME-exter. & $\mathrm{SD}$ & 2.36697 & 2.47034 & .268 \\
regulation & $\mathrm{M}$ & 19.4615 & 22.3078 & \\
Tidak & $\mathrm{SD}$ & 4.21536 & 4.92248 & .126 \\
termotivasi & $\mathrm{M}$ & 14.6923 & 14.3078 & \\
Total & $\mathrm{SD}$ & 3.27579 & 3.81629 & .785 \\
& $\mathrm{M}$ & 148.000 & 150.008 & \\
& $\mathrm{SD}$ & 16.7481 & 9.81888 & .703 \\
\hline
\end{tabular}

\section{Motivasi Intrinsik-to Know}

Sub variabel motivasi intrinsik-to know kedua kelompok sampel tidak mengalami ratarata perbedaan yang signifikan $(0.156>0.05)$. Kedua kelompok sampel menunjukkan sikap yang senang dan gembira tentang masing-masing olahraga yang dipraktikkan, mendapatkan teknik latihan yang baru atau teknik yang belum pernah dilakukannya, serta untuk mencari dan menemukan strategi berkompetisi yang baru.

Kedua kelompok sampel ini merupakan cabang olahraga unggulan di Provinsi NTT, sebab itu setiap atlet dari dua kelompok sampel ini memiliki tanggung jawab untuk berprestasi di kancah regional, nasional, dan internasional. Ini pun mendorong setiap atlet agar selalu berupaya mengembangkan teknik dan strategi latihan yang baru secara senang dan gembira. Meskipun keduanya tidak memiliki perbedaan signifikan, namun motivasi intrinsik-to know atlet atletik lebih rendah dari atlet tinju. Hal ini ditunjukkan dengan nilai rata-rata atlet atletik sebesar 24.2308 dan atlet tinju sebesar 25.6154.

\section{Motivasi Intrinsik-to Accomplish}

Sub variabel motivasi intrinsik-to accomplish kedua kelompok sampel tidak mengalami rata-rata perbedaan yang signifikan (0.097 > 0.05). Kedua kelompok sampel samasama mencari kepuasan pribadi dengan menguasai teknik latihan yang sulit, meningkatkan kelemahan-kelemahan baik secara teknik maupun strategi, menyempurnakan kemampuan, serta mendapatkan kegembiraan ketika mampu melakukan sebuah gerakan yang sulit.

Kedua atlet dari kelompok sampel intens untuk selalu berusaha memperbaiki dan menyempurnakan setiap kemampuan mereka. Rasa memiliki terhadap aktivitas olahraga (berlatih) sudah tinggi, sehingga atlet berlatih sambil mengembangkan berbagai teknik-teknik yang berpengaruh terhadap performa olahraganya. Meskipun keduanya tidak memiliki perbedaan signifikan, namun motivasi intrinsik-to accomplish atlet atletik lebih rendah dari atlet tinju. Hal ini ditunjukkan dengan nilai rata-rata atlet atletik sebesar 21.9231 dan atlet tinju sebesar 18.1538 .

\section{Motivasi Intrinsik-to Experience Stimulation}

Kontinum terakhir dari motivasi intrinsik ialah experience stimulation. Sub variabel motivasi intrinsik-to experience stimulation kedua kelompok sampel mengalami rata-rata perbedaan yang signifikan $(0.004<0.05)$. Perbedaan antara kedua kelompok sampel, ialah pada saat berolahraga, mereka merasa ditinggal pengalaman menarik. Kelompok sampel atletik lebih menunjukkan sikap polakan terhadap pernyataan tersebut, sedangkan kelompok sampel atlet tinju, tetap memiliki kesenangan saat berolahraga, meskipun ada pengalaman menarik lainnya yang rela Ia tinggalkan.

Atlet tinju lebih menunjukkan dominasi motivasi intrinsik-to experience stimulation. Hal ini ditunjukkan dengan nilai rata-rata atlet atletik sebesar 18.0769 dan atlet tinju sebesar 22.3077. Dengan demikian, atlet tinju memiliki motivasi olahraga yang lebih baik dari atlet atletik untuk mendapatkan sesasi dengan menstimulasi pengalaman gerak. Misalnya atlet tinju merasa senang jika dia dapat melakukan pukulan knock out (KO).

\section{Motivasi Ekstrinsik-Identified Regulation}

Sub variabel motivasi ekstrinsik-identified regulation kedua kelompok sampel tidak mengalami rata-rata perbedaan yang signifikan $(0.274$ 
$>0.05)$. Dengan berolahraga, kedua kelompok sampel sama-sama ingin menganggap bahwa seabagai salah satu cara untuk bertemu atau berkenalan dengan orang lain, pengembangan aspek-aspek dalam diri, mencari kegunaan lain dalam setiap kehidupan dengan berolahraga, serta tetap menjaga hubungan atau koneksi yang baik dan harmonis dengan teman-teman lainnya. Kedua kelompok sampel melakukan kegiatan olahraga untuk alasan dari luar, yaitu untuk mencapai keuntungan atau tujuan personal.

Atlet yang berpartisipasi dalam olahraga karena atlet merasa partisipasinya memberikan kontribusi atau sumbangan untuk kemajuan pribadinya. Misalnya atlet atletik melakukan atletik melakukan latihan sprinter untuk meningkatkan kecepatan larinya, meskipun atlet mengalami kelelahan. Meskipun keduanya tidak memiliki perbedaan signifikan, namun motivasi ekstrinsikidentified regulation atlet atletik lebih tinggi dari atlet tinju. Hal ini ditunjukkan dengan nilai ratarata atlet atletik sebesar 25.0769 dan atlet tinju sebesar 23.9231.

\section{Motivasi Ekstrinsik-Introjected Regulation}

Sub variabel motivasi ekstrinsik-introjected regulation kedua kelompok sampel tidak mengalami rata-rata perbedaan yang signifikan $(0.268>0.05)$. Kedua kelompok sampel menunjukkan perasaan yang sama untuk berolahraga, karena penting menjaga kondisi performa maupun kesehatan atlet. Serta itu, dengan berolahraga setiap atlet merasa diri lebih baik, dirinya akan memiliki performa yang buruk, jika tidak menyediakan waktu untuk berolahraga, serta memang sebagai atlet, dirinya harus melakukan olahraga secara teratur. Meskipun keduanya tidak memiliki perbedaan signifikan, namun motivasi ekstrinsik-introjected regulation atlet atletik lebih tinggi dari atlet tinju. Hal ini ditunjukkan dengan nilai rata-rata atlet atletik sebesar 24.5385 dan atlet tinju sebesar 23.4615.

Alhasil kedua kelompok atlet pun memiliki motivasi berolahraga hanya semata-mata untuk menghindari diri dari sebuah kesalahan atau cemohan dari pengurus, pelatih, maupun sesama atlet. Atlet berpartisipasi dalam olahraga karena dirinya merasa tekanan untuk berada dalam kondisi yang baik untuk alasan tertentu dan merasa malu atau malu ketika mereka tidak dalam performa terbaik.

\section{Motivasi Ekstrinsik-External Regulation}

Sub variabel motivasi intrinsik-external regulation kedua kelompok sampel tidak meng- alami rata-rata perbedaan yang signifikan $(0.126$ $>0.05$ ). Dengan berolahraga, kedua kelompok sampel merasa mereka akan dihormati oleh setiap orang yang mengenalinya, menjadikan diri sebagai atlet yang berpengaruh atau terkenal. Selain itu, dengan berolahraga orang-orang terdekat akan menjadikan dirinya sebagai model atau bagian terpenting dalam olahraga, serta ingin memberikan jaminan kepada orang lain bahwa mereka dapat melakukan kegiatan olahraga dengan baik.

Atlet berolahraga bukan untuk proses aktualisasi diri guna mendapatkan kegembiraan, kepuasan, dan kenikmatan namun partisipasi atlet dalam berolahraga hanya karena dengan imingiming eksternal, misanya bonus prestasi. Meskipun keduanya tidak memiliki perbedaan signifikan, namun motivasi intrinsik-external regulation atlet atletik lebih rendah dari atlet tinju. Hal ini ditunjukkan dengan nilai rata-rata atlet atletik lebih besar atlet tinju sebesar 19.4615 dan atlet tinju sebesar 22.3078.

\section{Tidak Termotivasi}

Sub variabel tidak termotivasi kedua kelompok sampel tidak mengalami rata-rata perbedaan yang signifikan $(0.785>0.05)$. Pada sub variabel ini, kedua kelompok atlet tidak mengangagap kontinjensi antara tindakan dengan hasil tindakan. Atlet mengalami perasaan ketidakberdayaan serta rendahnya pengendalian atas perasaan-perasaan tersebut. Saat terlibat dalam latihan olahraga, atlet tidak menunjukkan sikap motivasi, baik secara intrinsik maupun secara ekstrinsik.

Pada kondisi seperti ini (amotivation), mereka tidak lagi mengidentifikasi alasan yang baik untuk berpartisipasi dalam proses latihan. Atlet bahkan dimungkinkan membuat keputusan untuk berhenti berlatih dari kegiatan olahraganya. Kedua kelompok atlet menunjukkan pernyataan yang positif untuk berpikir terlibat dalam kegiatan olahraga. Namun dirinya masih ingin menjadi bagian dari proses latihan, serta memiliki respon dapat mencapai tujuan yang diaturnya sendiri. Meskipun keduanya tidak memiliki perbedaan signifikan, namun atlet atletik menunjukkan sikap tidak termotivasi (amotivation) yang lebih tinggi dari atlet tinju. Hal ini ditunjukkan dengan nilai rata-rata atlet atletik sebesar 14.6923 dan atlet tinju sebesar 14.3078.

\section{Motivasi Berolahraga}

Atlet atletik dan atlet tinju memiliki tanggung jawab untuk berprestasi. Untuk berprestasi, 
motivasi merupakan dasar untuk semua usaha olahraga dan prestasi (Adeyeye, Vipene, \& Asak, 2013), motivasi juga merupakan salah satu faktor penting dan efektif untuk perbaikan performa olahraga atlet (Nezhad \& Sani, 2014), serta sebagai kekuatan yang bergerak dalam tugas yang menantang dan sulit (Murtaza, Ahmad, Imran, Ahmad, \& Singh, 2013). Hasil penelitian menunjukkan bahwa tidak ada perbedaan yang signifikan antara rata-rata motivasi berolahraga atlet atletik dan atlet tinju, yaitu nilai signifikansi lebih besar dari $0.05(0.703>0.05)$. Tidak adanya perbedaan ini ada-lah bentuk pengukuran secara keseluruhan dari variabel motivasi berolahraga menggunakan SMS. Meskipun keduanya tidak memiliki per-bedaan signifikan, namun motivasi berolahraga atlet atletik lebih rendah dari atlet tinju. Hal ini ditunjukkan dengan nilai rata-rata atlet atletik sebesar 148.000 dan atlet tinju sebesar 150.008 .

Setiap atlet diharapkan menuju pada titik kontinum terakhir, yaitu motivasi intrinsik. Sehingga apa yang atlet lakukan dalam kegiatannya olahranya (latihan maupun kompetisi) sematamata untuk kesenangan atau kegembiraannya tanpa adanya iming-iming lain yang bersifat eksternal. Kontinum ini (motivasi internal) mendorong atlet untuk mengembangkan performa yang dimulai dari dalam diri sendiri. Orientasi motivasi intrinsik mengendalikan atlet atletik dan tinju untuk berpartisipasi dalam kegiatan prestasi untuk alasan internal (misalnya, untuk bersenang-senang, kesenangan, maupun penguasaan pribadi (Amorose \& Horn, 2000).

Motivasi intrinsik yang lebih besar dalam kondisi yang mendukung perasaan atlet-atlet untuk lebih otonom, kompeten, dan keterkaitan dengan kegiatan olahraga (O'Rourke, Smith, Smoll, \& Cumming, 2012), dan bahkan dapat memotivasi atlet untuk menyumbangkan ide-ide kreatif dan inovatif selama proses latihan maupun kompetisi (Edrak, Yin-Fah, Gharleghi, \& Seng, 2013) guna memperbaiki performa dn kualitas latihannya sendiri.

\section{SIMPULAN DAN SARAN}

\section{Simpulan}

Simpulan yang dapat ditarik dari hasil analisis dan pembahasan penelitian adalah bahwa motivasi berolahraga atlet atletik berkategori baik dengan jumlah responden sebanyak 9 orang (69.2\%). Sedangkan atlet tinju adalah baik dengan jumlah responden sebanyak 12 orang $(92.3 \%)$. Motivasi berolahraga antara atlet atletik dan atlet tinju ditemukan nilai rata-rata atlet tinju lebih tinggi daripada atlet atletik, namun nilai standar deviasi atlet atletik lebih tinggi daripada atlet tinju. Sedangkan nilai signifikansi adalah 0.703 (> 0.05) sehingga tidak ada perbedaan yang signifikan antara rata-rata motivasi berolahraga atlet atletik dan atlet tinju.

Pada subvariabel motivasi intrinsik-to experience stimulation, terdapat perbedaan signifikan antara rata-rata sub variabel motivasi intrinsik-to experience stimulation atlet atletik dan atlet tinju $(0.004<0.05)$. Atlet atletik maupun atlet tinju sebagai cabang olahraga unggulan, sehingga atlet-atlet yang berlatih maupun berkompetisi perlu diperhatikan model motivasi yang baik dengan benar (intrinsik motivasi) sehingga tetap memiliki semangat nasionalisme terhadap Provinsi NTT dalam kompetisi olahraga.

\section{Saran}

Atlet atletik maupun atlet tinju sebagai cabang olahraga unggulan Provinsi NTT, sehingga atlet-atlet yang berlatih maupun berkompetisi perlu diperhatikan model motivasi yang baik dengan benar (intrinsik motivasi) sehingga tetap memiliki semangat nasionalisme terhadap Provinsi NTT dalam kompetisi olahraga.

Pemberian bonus kepada atlet sebaiknya ditempatkan di akhir kompetisi. Hal ini dilakukan agar kegiatan olahraga yang dilakukan atlet tidak berorientasi eskternal, melainkan kesadaran berprestasi yang diafirmasi oleh stakeholder jika kelak berprestasi sebagai bentuk penghargaan.

\section{DAFTAR PUSTAKA}

Adeyeye, F.M., Vipene, J.B., \& Asak, D.A. (2013). The impact of motivation on athletic a achievement: A case study of the $18^{\text {th }}$ national sport festival, Lagos, Nigeria. Academic Research International, 4(5), 378-383.

Amorose, A. J., \& Horn, T. S. (2000). Intrinsic motivation: Relationship with collegiate athletes' gender, scholarship status, and perceptions of their coaches' behavior. Journal of Sport \& Exercise Psychology, 22, 63-84.

Barkoukis, V., Tsorbatzoudis, H., Grouios, G., \& Sideridis, G. (2008). The assessment of intrinsic and extrinsic motivation and amotivation: Validity and reliability of the Greek version of the academic motivation scale. Assessment in Education: 
Principles, Policy \& Practice, 15(1), 3955.

Bhagirathi, S.E. (2008). Relationship of anxiety and achievement motivational to goal keeping among secondary school level girls hockey players. Journal of Exercise Science and Physiotheraphy, 4(2), 115118.

Davies, S. \& Armstrong, M. (1989). Psychological factors in competitive sport $\left(l^{s t} e d\right)$. Philadelphia: Falmer Press, Taylor $\&$ Francis Inc.

Duda, J.L. \& Treasure, D.C. (2001). Toward optimal motivation in sport: Fostering athletes' competence and sense of control. In William, J.N. (Ed.). Applied sport psychology: Personal growth to peak performance $\left(4^{\text {th }} e d\right)$. California: Mayfield Publishing Company.

Edrak, B.B., Yin-Fah, B.C., Gharleghi, B., \& Seng, T.K. (2013). The effectiveness of intrinsic and extrinsic motivations: A study of Malaysian amway company's direct sales forces. International Journal of Bussiness and Social Science, 4(9), 96103.

Gillet, N., Vallerant, R.J., Amoura, S., \& Baldes, B. (2010). Influence of coaches' autonomy support on athletes' motivation and sport performance: A test of the hierarchical model of intrinsic and extrinsic motivation. Psychology of Sport and Exercise, 11, 155-161.

Gillison, F., Osborn, M., Standage, M., \& Skevington, S. (2009). Exploring the experience of introjected regulation for exercise across gender in adolescence. Psychology of Sport and Exercise, 10, 309319.

Jarvis, M. (2006). Sport psychology: A student's handbook ( $\left.1^{\text {st }} e d\right)$. New York: Routledge.

Kaya, S., Kabakci, A.C., \& Dogan, A.A. (2015). Differences in motivation for participating sport activities according to sport branches. International Journal of Science Culture and Sport, 3(1), 44-53.

Maksum, A. (2011). Psikologi olahraga: Teori dan aplikasi (cet. 2). Surabaya: Unesa University Press.

Murtaza, S.T., Ahmad, T., Imran, M., Ahmad, S., \& Singh, R.P. (2013). A comparative study on sports achievement motivation and sensation seeking among Indian athletes. Shodh Sangam, 2(1), 1-6.

Nezhad, M.A.H. \& Sani, K.D. (2012). The effect of intrinsic motivation and sport commitment on the performance of Iranian national water polo team. International Research Journal of Applied and Basic Sciences, 3(6), 1173-1177.

O'Rourke, D.J., Smith, R.E., Smoll, F.L., \& Cumming, S.P. (2012). Parent-initiated motivational climate, self-esteem, and autonomous motivation in young athletes: Testing propositions from achievement goal and self-determination theories. Child Development Research, 1-9.

Pelletier, L.G., Fortier, M.S., Vallerad, R.J., Briere, N.M., Tuson, K.M., \& Blais, M.R. (1995). Toward a new measure of intrinsic motivation, extrinsic motivation, and amotivation in sport: The sport motivation scale (sms). Journal of Sport \& Exercise Psychology, 17, 35-53.

Rao, Y.M. \& Kishore, Y. (2014). A study of achievement motivation of inter university sports participants. International Journal of Physical Education, Sport, and Health, 1(2), 1-5.

Ryan, R.M. \& Deci, E.L. (2000). Intrinsic and extrinsic motivation: Classic definition and new directions. Contemporary Educational Psychology, 25, 54-67.

Ryan, R.M. \& Deci, E.L. (2000). Selfdetermination theory and the facilitation of intrinsic motivation, social development, and well-being. American Psychological Association, 55(1), 68-78.

Shafizadeh, M. \& Gray, S. (2011). Development of a behavioral assessment system for achievement motivational in soccer mathches. Journal of Quantitative Analysis in Sport, 7(3), 1-14.

Slathia, R., Singh, H., \& Dar, H.A. (2015). Motivation among male and female cricket players of Jammu division: A comparative study. International Journal in Physical \& Applied Science, 2(4), 53-56.

Teo, E.W., Khoo, S., Wong, R., Wee, E.H., Lim, B.H., \& Rengasamy, S.S. (2015). Intrinsic and extrinsic motivation among adolescent ten-pin bowlers in Kuala Lumpur, Malaysia. Journal of Human Kinetics, 45, 241-251. 